\title{
The fracture toughness of martensite islands in dual-phase DP800 steel
}

\author{
Chunhua Tian ${ }^{1, a)}$ (D), Christoph Kirchlechner ${ }^{2}$ \\ ${ }^{1}$ Max-Planck-Institut Für Eisenforschung GmbH, 40237 Düsseldorf, Germany \\ ${ }^{2}$ Institute for Applied Materials, Karlsruhe Institute of Technology, 76344 Eggenstein-Leopoldshafen, Germany \\ a) Address all correspondence to this author. e-mail: c.tian@mpie.de \\ Received: 31 October 2020; accepted: 2 March 2021; published online: 17 March 2021
}

In situ microcantilever bending tests were performed on martensite islands in a dual-phase (DP) steel to extract the fracture toughness of martensite at the microscale and to understand damage initiation during forming of DP steels. All microcantilevers were produced through FIB milling. The martensite islands do not exhibit linear elastic brittle fracture; instead, significant ductile tearing is observed. The conditional fracture initiation toughness extracted by definition and by Pippan's transfer criterion is $K_{i}=6.5 \pm 0.4 \mathrm{MPa} \mathrm{m}^{1 / 2}$ and $K_{i, 2}=10.1 \pm 0.3 \mathrm{MPa} \mathrm{m}^{1 / 2}$, respectively. The obtained value is well-represented by the strength-toughness trend of other ferritic steel grades. Considering the yield stress of the same martensite island, we found that crack initiation can occur only in very large martensite islands or in a banded or agglomerated martensite structure.

\section{Introduction}

The class of dual-phase (DP) steels is widely applied in automotive industries. Continuous yielding behavior, easily adjustable mechanical properties and low alloying contents characterize their attractive features [1-4]. A main issue still raising large research interest is their damage initiation and evolution mechanisms, which mainly arise from the two phases and their huge mechanical heterogeneity. Martensite islands are believed to be one of the most susceptible damage initiation sites primarily recognized by post-mortem morphology observation through microscopes [5-7]. However, a quantitative assessment of their fracture toughness is still pending.

Micromechanical testing became an important tool to locally investigate mechanical properties by extracting the targeted microconstituents $[8,9]$ with focused ion beam (FIB) milling. This also applies for fracture properties. Most of the previous small-scale fracture mechanical studies focused on brittle materials, in particular thin films or layered structure [10-12]. Due to the small sample size, the assumptions of the linear elastic fracture models are often not met and small-scale elastic plastic fracture mechanics (EPFM) needs to be applied [13-15]. So far, most materials investigated with small-scale EPFM are model materials (e.g., ultrafine-grained tungsten or tungsten single crystals), and the application of microscopic EPFM to daily used and industrially produced microconstituent still remains rare.

This work aims at measuring the fracture properties of martensite islands to quantitatively assess the damage initiation of an advanced dual-phase DP800 steel.

\section{Results}

\section{Microstructure and chemical composition}

The DP steel microstructure is comprised of two phases, namely the matrix ferrite and the dispersed martensite island as shown in Fig. 1a. The latter has a much smaller grain (colony) size compared to the former and exhibits irregular shapes (Fig. 1b). Further, the colored inverse pole figure (IPF) of an EBSD (electron backscattered diffraction) mapping clearly illustrates that the martensite islands exhibits a complex substructure with subboundaries called packets, blocks and laths. As expected, they are following the K-S orientation relationship with the prior austenite grain [16]. Theoretically, 24 variants with six in each of four packets should be formed inside one prior austenite grain. However, in our case the martensite islands consist typically of one or two packets-which is also common in DP steels [17]. 

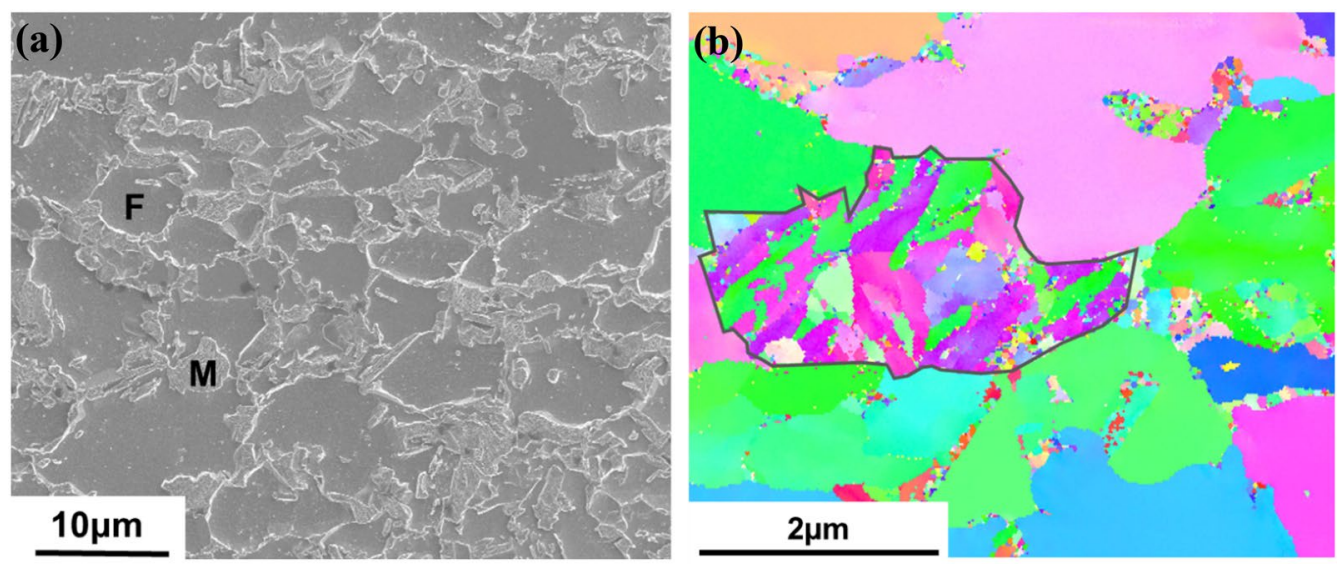

Figure 1: (a) Representative microstructure of DP steel etched by Nital solution, showing ferrite matrix (F) and martensite islands (M). (b) An IPF of a martensite island, showing the subboundaries. The island is bordered by a black solid line for clarity.

Besides the microstructure, the chemical composition is also characterized. $\mathrm{Mn}, \mathrm{Cr}$ and $\mathrm{Si}$ are predominantly homogeneously distributed in both phases, as can be seen from APT (atom probe tomography) measurements (Fig. 2) of an area containing both martensite and ferrite. The chemical content of ferrite is $1.90 \pm 0.14$ at.\% $\mathrm{Mn}, 0.74 \pm 0.09$ at.\% $\mathrm{Cr}$ and $0.41 \pm 0.08$ at.\% Si. Here, the error bar is defined as the standard error of the mean. Martensite has a comparable content of the three elements, with $2.19 \pm 0.20$ at. $\% \mathrm{Mn}, 0.97 \pm 0.04$ at.\% $\mathrm{Cr}$ and $0.54 \pm 0.04$ at.\% Si. However, a large difference exists for the carbon content. Carbon locates mainly in martensite with $3.77 \pm 0.20$ at.\% while very scarcely in ferrite with only $0.06 \pm 0.03$ at.\% (see Fig. $2 a$, b). It tends to segregate at defects like dislocations, subboundaries, in particular along the phase boundary. No carbides formation is observed in the martensite of this particular DP800, while it is clearly noted that depending on manufacturer and process this can change considerably.

(a)

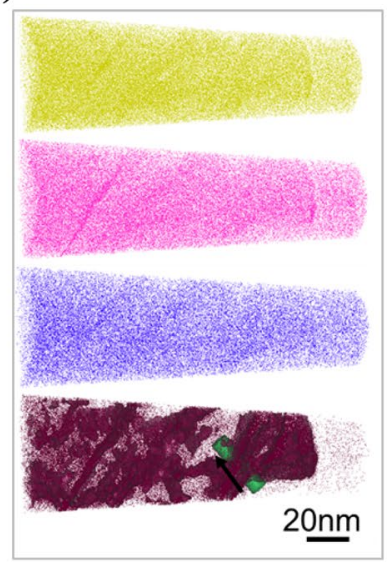

\section{Fracture properties}

Figure 3 shows a representative microcantilever exhibiting fracture of the martensite island and negligible deformation of the softer ferrite. The force initially shows a linear (and elastic) increase, pronounced plasticity and subsequently the force decreases with displacement (Fig. 3a). The snapshots in Fig. 3c obtained from in situ SEM imaging are labeled in the load displacement curve in Fig. 3a. The FIB-notch gradually grows to a natural crack exhibiting extensive crack blunting (see Fig. 3c.5). Hence, the observed fracture behavior is stable with pronounced ductility near the crack tip. This is consistent with macroscopic observations of lath martensite fracture, which exhibits brittle transgranular cleavage behavior only at low temperature, while it shows a typical dimple ductile fractography at room temperature [18-20]. Massive plastic deformation is evident, for instance by slip trace aligned approximately $45^{\circ}$ to the horizontal direction near the crack tip.

Figure 2: Chemical distribution of $\mathrm{Mn}, \mathrm{Si}, \mathrm{Cr}$ and $\mathrm{C}$ in an APT tip containing a ferrite-martensite boundary. (a) Spatial distribution of four main elements $\mathrm{Mn}, \mathrm{Cr}$, Si and C. (b) 1D concentration profile along the green cylinder in (a). Left side is ferrite and right side martensite.

(b) F/M interface

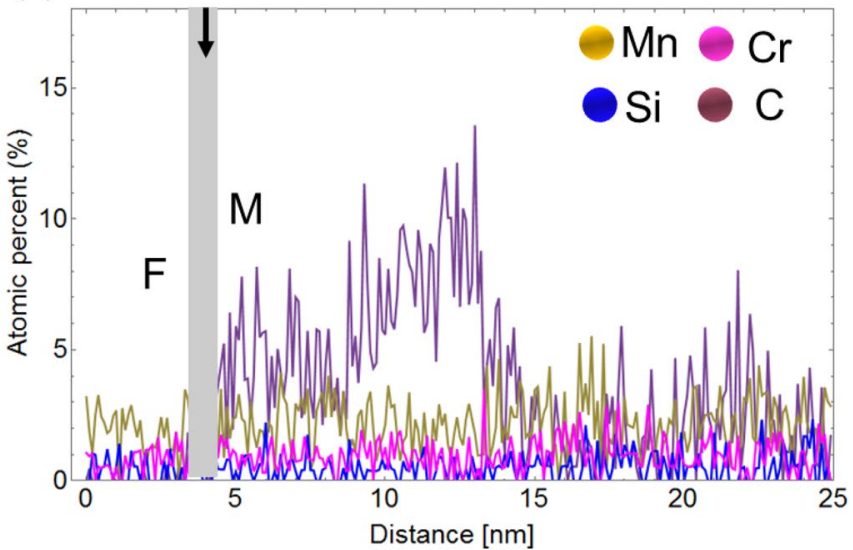


(a)

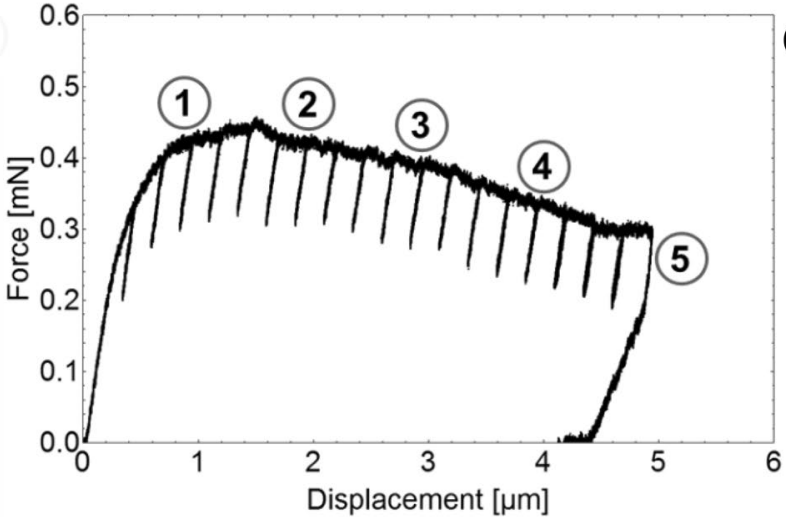

(b)

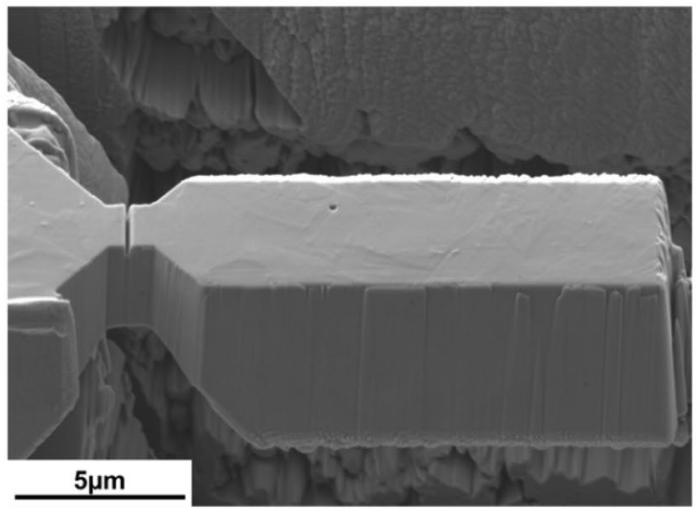

(c)
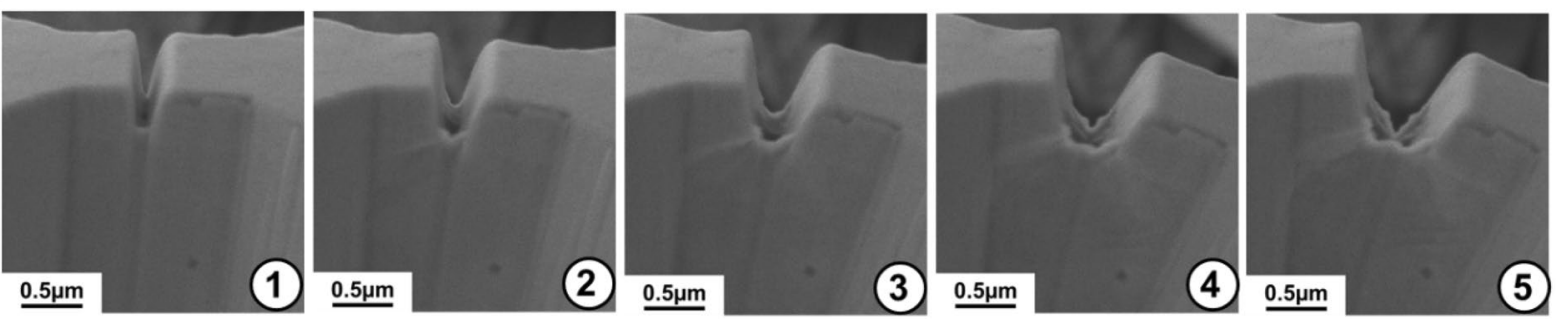

Figure 3: (a) The representative force-displacement curve of a tested sample exhibiting crack growth. (b) The corresponding as-milled microcantilever. (c) Snapshots showing the crack evolution corresponding to unloading states 1 to 5.

(a)

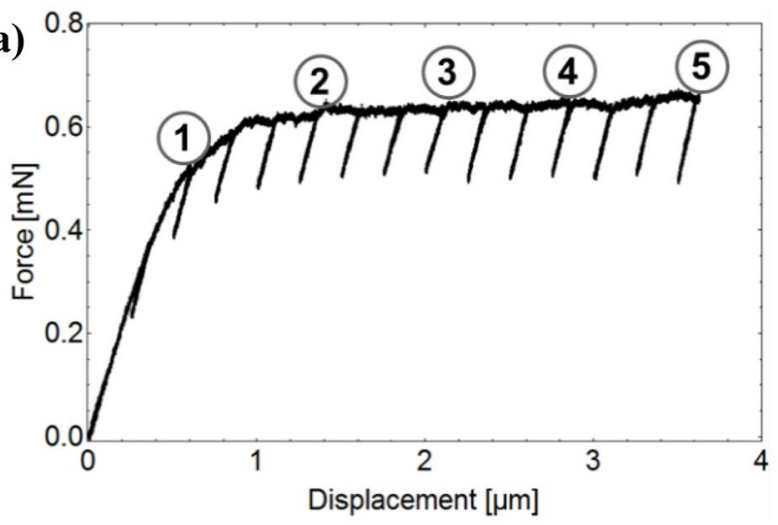

(b)

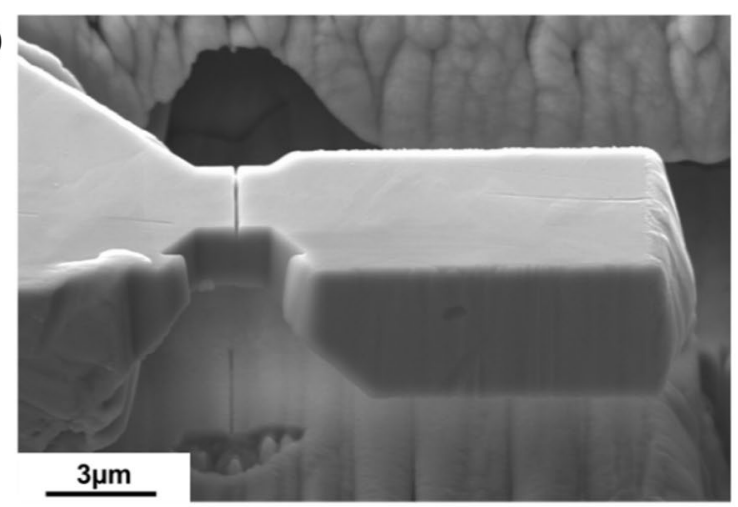

(c)
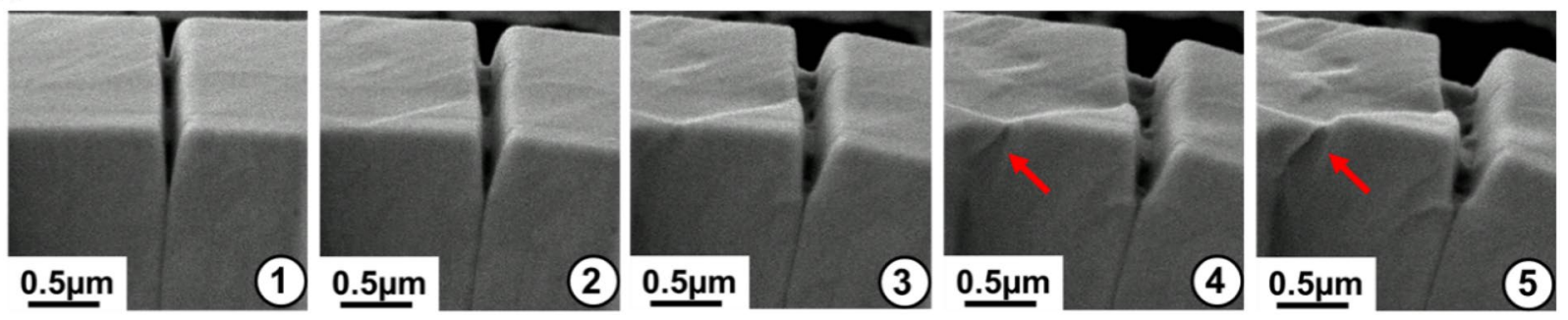

Figure 4: (a) Representative force-displacement curve of a sample exhibiting negligible crack growth in martensite but pronounced ferrite plasticity. (b) The as-milled microcantilever. (c) The snapshots showing the crack evolution corresponding to unloading states 1 to 5 . The arrow in (4) and (5) indicates massive plasticity far from the notch. 

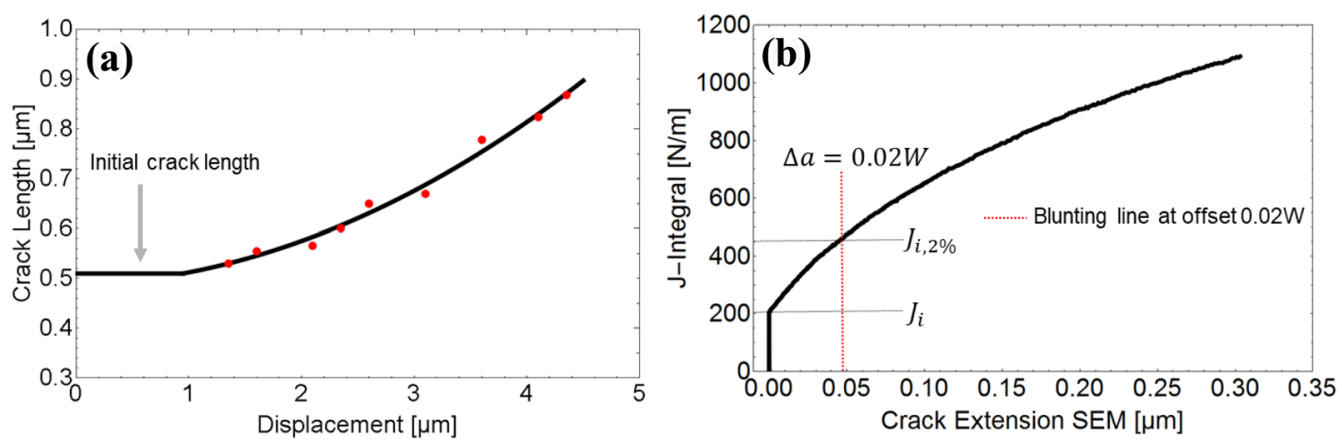

Figure 5: (a) The measured crack evolution versus displacement; (b) a representative $J-R$ curve corresponding to the sample in Fig. 3 . It labels out two approaches of determining the crack initiation toughness.

Figure 6: Compare the influence of polynomial fit degree on the determined fracture toughness value.

In some cases, the plastic deformation of the softer ferrite cannot be neglected anymore. Then, the force-displacement curve (Fig. 4) does not show a drop and the unloading stiffness generally remains constant. The notch-tip is blunting but no crack extension is visible in the SEM. Also, a significant amount of plasticity is observed in ferrite close to the clamping end (Fig. 4c, arrow).

After carefully screening for ferrite plasticity we discard 25 out of 30 samples because of negligible crack growth but extensive ferrite plasticity, i.e., only in 5 out of 30 cantilevers are further analyzed to assess the fracture toughness of martensite.

The crack extension is measured from in situ snapshots and plotted versus displacement (see Fig. 5a). The red points are the measured crack length at the end of the unloading sequence. The crack extension is fitted by a polynomial fit (black solid line). The crack length remains almost constant to a displacement of $\sim 1 \mu \mathrm{m}$, as indicated by the arrow in Fig. $5 \mathrm{a}$. Based on the load-displacement data and the crack extension curve, the $J$-integral was obtained following Eqs. (4)-(6) in "Experimental procedure" section (see crack resistance curve in Fig. 5b).

The R-curve is used to extract the crack initiation toughness $J_{i}$ (Fig. $5 \mathrm{~b}$ ) - which is, by definition, the transition point from crack blunting to crack growth stage and known to be less geometry dependent than the subsequent R-curve [21]. However, an unambiguous identification of the initiation

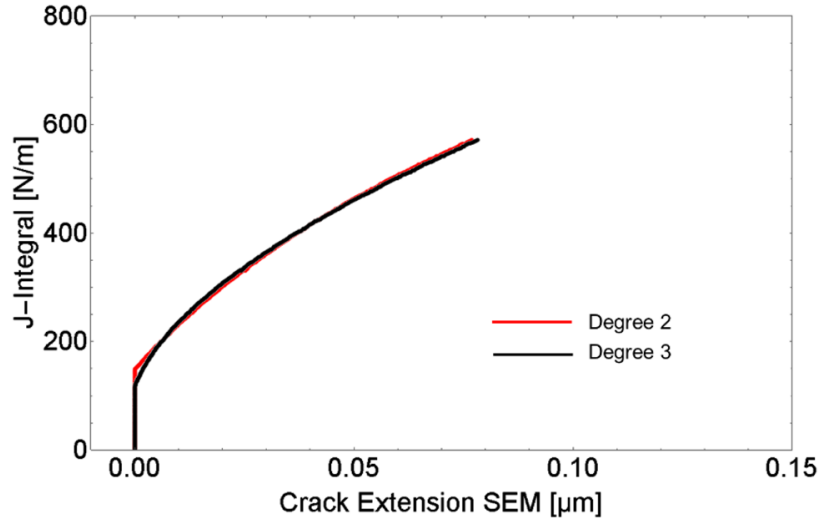

toughness is in most cases not possible. Therefore, we additionally use Pippan's transfer criterion of the $0.02 \mathrm{~W}$ blunting line offset to determine the crack initiation toughness as $J_{i, 2 \%}[22,23]$. This transfer criterion can further minimize the influence of polynomial fit degree applied for the crack length versus displacement (see Fig. 6). For instance, the $J_{i, 2} \%$ determined by $0.02 \mathrm{~W}$ transfer criterion equals $359 \mathrm{~N} / \mathrm{m}$ for a polynomial fit of degree 2 (used in analysis) and $361 \mathrm{~N} / \mathrm{m}$ for degree 3 , respectively. By contrast, the $J_{i}$ through intersection of fitting line with initial crack length is affected much more, comparing $147 \mathrm{~N} / \mathrm{m}$ for polynomial fit of degree 2 and $114 \mathrm{~N} / \mathrm{m}$ for degree 3 .

We summarized all $J-R$ curves of the five successfully tested beams in Fig. 7. To a large extent, they coincide with each other. In particular, the crack initiation seems to appear at a similar value for all five cantilevers, and the curve deviates during subsequent crack growth (see Fig. 7a, b). Finally, for comparison, we converted the $J$-integral to the stress intensity $K$ using Eq. (1).

$$
K=\sqrt{J \frac{E}{\left(1-v^{2}\right)}} .
$$



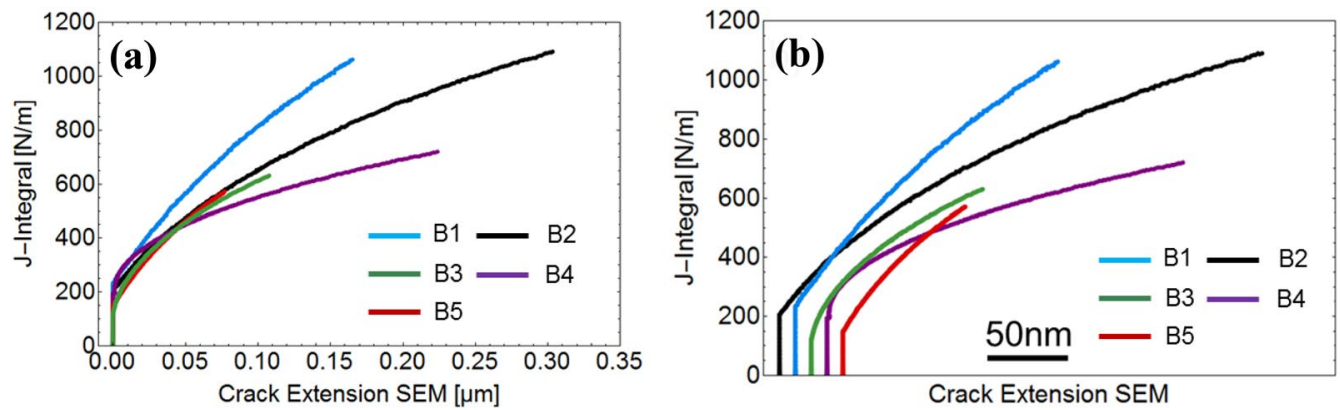

Figure 7: (a) A comparison of $J-R$ curves of five successfully tested samples and (b) a better visualization of (a) with shifted $J-R$ curves.

Table 1 summarizes all five beams including both geometrical dimensions and fracture properties. Note that the $\mathrm{a} / \mathrm{W}$ ratio for our samples is mainly between 0.2 and 0.3 , smaller than 0.4-0.5 proposed in ASTM 1820. There are two reasons choosing a smaller $a / W$ ratio. First, due to the FIB milling technique, a certain limited aspect ratio of milling depth to milling width can be achieved. Already well before this maximum aspect ratio one deviates from a sharp notch. We decided to sacrifice the $a / W$ ratio in order to get sharp notches [15]. Second, the small martensite islands do not allow extensive crack. We try to keep the initial notch small in order to see crack blunting and stable crack growth. It is evident that the crack initiation toughness neither by $K_{i}$ nor by Pippan's transfer criterion varies significantly among the five beams. During the remainder of this paper, if not specifically pointed, we discuss and compare only $K_{i, 2 \%}$, as the discussion would be identically for $K_{i}$. On average, the crack initiation toughness of martensite island is $J_{i, 2 \%}=423 \pm 22 \mathrm{~J} / \mathrm{m}^{2}$ and $K_{i, 2 \%}=10.1 \pm 0.3 \mathrm{MPa} \mathrm{m}^{1 / 2}$.

\section{Discussion}

\section{Did we obtain a geometry-independent plane-strain fracture toughness?}

Within this work, we aimed for the fracture toughness of martensite as material property, i.e., as geometry-independent plane-strain critical stress intensity factor $K_{\mathrm{IC}}$. Macroscopically, stringent requirements are listed both in E399 and in
E1820 $[21,24,25]$ to ensure a plane-strain state. For instance, a high-triaxiality region should be considerably larger than the plastic zone size and the ductile tearing section at the two beam edges. The former is mainly guaranteed by the beam thickness, while the latter by beam width according to the definition of our work. To assure plane-strain conditions, a critical sample dimension $D_{\mathrm{EPFM}}$ (Eq. 2) needs to be present, also for the micron scale $[15,26]$.

$$
D_{\mathrm{EPFM}}=10 \ldots 50 \frac{J_{I c}}{\sigma_{y}},
$$

where $J_{\mathrm{Ic}}$ is the critical $J$-integral for Mode $I$ fracture and $\sigma_{y}$ is the yield strength of the tested material. If we consider the obtained J-integral $\left(423.0 \pm 22.1 \mathrm{~J} / \mathrm{m}^{2}\right)$ and the yield strength of martensite islands in our DP800 steel $(2880 \pm 49 \mathrm{MPa})$ [27], the critical sample dimension $D_{\text {EPFM }}$ ranges from 1.4 to $6.8 \mu \mathrm{m}$ that sets the lower limit of the sample thickness $W$ and width $B$. As shown in Table 1, this condition is not fulfilled. What is obtained here can be rather considered as conditional fracture toughness for this dimension. Unfortunately, due to the limited martensite island size and the considerable large fracture toughness of martensite, one cannot obtain a geometry-independent fracture toughness under plane-strain conditions in this DP800 steel grade. Still, the results obtained here could be used as an input parameter for modeling damage initiation [28].
TABLE 1: Summary of five successfully tested beams, including both the geometrical dimensions and fracture property.

\begin{tabular}{lccccccccccc}
\hline \hline & $a_{0}$ & $W$ & $a / W$ & $B$ & $L$ & $L / W$ & $J_{i}$ & $K_{i}$ & $J_{i, 2 \%}$ & $K_{i, 2 \%}$ \\
\hline B1 & 0.49 & 1.84 & 0.26 & 1.69 & 9 & 5 & 233.5 & 7.5 & 485.8 & 10.8 \\
B2 & 0.51 & 2.30 & 0.22 & 1.59 & 9 & 4 & 205.0 & 7.0 & 456.8 & 10.5 \\
B3 & 0.43 & 1.86 & 0.23 & 1.00 & 12 & 6 & 122.6 & 5.4 & 405.9 & 9.9 \\
B4 & 0.38 & 1.73 & 0.22 & 1.46 & 11 & 6 & 193.9 & 6.8 & 407.7 & 9.9 \\
B5 & 0.50 & 1.47 & 0.33 & 1.64 & 10 & 6.8 & 147.4 & 6.0 & 358.6 & 9.3 \\
Average & & & & & & & & 180 & 6.5 & 423 & 10.1 \\
Standard error & & & & & & & \pm 20 & \pm 0.4 & \pm 22 & \pm 0.3 \\
\hline \hline
\end{tabular}

Unit of the geometry parameters $a_{0}, W, B, L$ is all $\mu \mathrm{m}$ and of $J$ is $J / m^{2}$ while of $K$ is MPa $\mathrm{m}^{1 / 2}$. 


\section{Comments on deviation of the crack resistance curve during crack growth}

Although the conditional fracture initiation toughness of five beams is consistent with one another, the crack resistance curves deviate with further crack extension. One possible explanation could be the slightly different $a / W$ ratio of the investigated cantilevers. The top most curve in Fig. 7a was measured on the cantilever with a high $a / W$ ratio, in other words, shorter left ligament. While the crack initiation is less influenced by the ligament length, the crack resistance curve depends strongly on initial crack depth at macroscopic investigations [29, 30]. However, this trend was recently not observed at the micrometer length scale [15], where shorter ligaments lead to higher crack resistance.

Hence, the more likely explanation of the strong variation in crack resistance curve is the strong variation of microstructure in the 5 tested beams: Neither the number of probed variants nor the orientation of the martensite island is identical for all the samples. While the influence of the local microstructure seems to be negligible for crack initiation, crack growth is obviously significantly influenced by the hierarchical microstructure of the martensite.

Another factor that might lead to the deviation of crack growth resistance curve is the roughness of the crack front due to the heterogenous microstructure in the martensite island, as shown in Fig. 8. The data were obtained by FIB serial sectioning of the tested cantilever. In Fig. 8, the crack length exhibits a minimum length of $717 \mathrm{~nm}$ and a maximum length of $974 \mathrm{~nm}$. In the in situ SEM micrographs, the crack length was measured at the front face of the cantilevers and is $840 \mathrm{~nm}$. It is expected and well-known from the literature [15] that the variation of the crack length at crack initiation is smaller compared to the region showing pronounced crack growth (Fig. 8). Hence, the crack front roughness has a larger influence on the R-curve behavior than on the crack initiation toughness value.

\section{Comparison with other Fe-based materials}

The obtained fracture toughness of DP800 martensite islands is substantially lower than that of tested bulk martensite (can reach dozens of $\mathrm{MPa} \mathrm{m}{ }^{1 / 2}$ ) which has a similar carbon content but much larger substructure size [20,31].

Recently, the toughness of different steels at the micron scale including white etching layers - which might be similar to martensite in terms of carbon supersaturation, but not in terms of microstructure-was correlated with the hardness via an empirical equation $K_{Q}=\frac{10^{4}}{\mathrm{HV}}$, where $\mathrm{HV}$ is the Vickers hardness [23]. The Vickers hardness of martensite was statistically reported following $H_{V}=0.4\left(\sigma_{Y}-100\right)$ [32]. In this empirical way, the estimated fracture toughness $K_{\mathrm{IQ}}$ is $8.8-9.2 \mathrm{MPa} \mathrm{m}^{1 / 2}$, which is close to our experimental results of $10.1 \pm 0.3 \mathrm{MPa} \mathrm{m}^{1 / 2}$. Hence, the martensite in DP800 follows the expected trend for steels.

Unraveling the reason for the observed toughness is more complicated and only a brief speculation is presented here. The carbon content of martensite and its distribution plays a critical role in the fracture toughness of Fe-based alloys [33, 34]. Supersaturated carbon has an adverse effect on fracture toughness, such as in severely deformed pearlite. The lamellar shape cementite in pearlitic steels is dissolved into the ferrite matrix upon severe plastic deformation (e.g., wire drawing), reducing strain hardening ability of soft ferrite. This partly results in an inferior fracture toughness $[33,34]$. The nominal carbon content in our material $(0.13 \mathrm{wt} \%)$ is much lower than that in the pearlitic rail steel $(0.72 \mathrm{wt} \%)$ where WELs are formed $[23,35]$. However, in our case almost the entire carbon is present in the martensite (see Fig. 2) with an average amount similar to carbon content of 3 at.\% present in WELs [35]. Besides, both show a

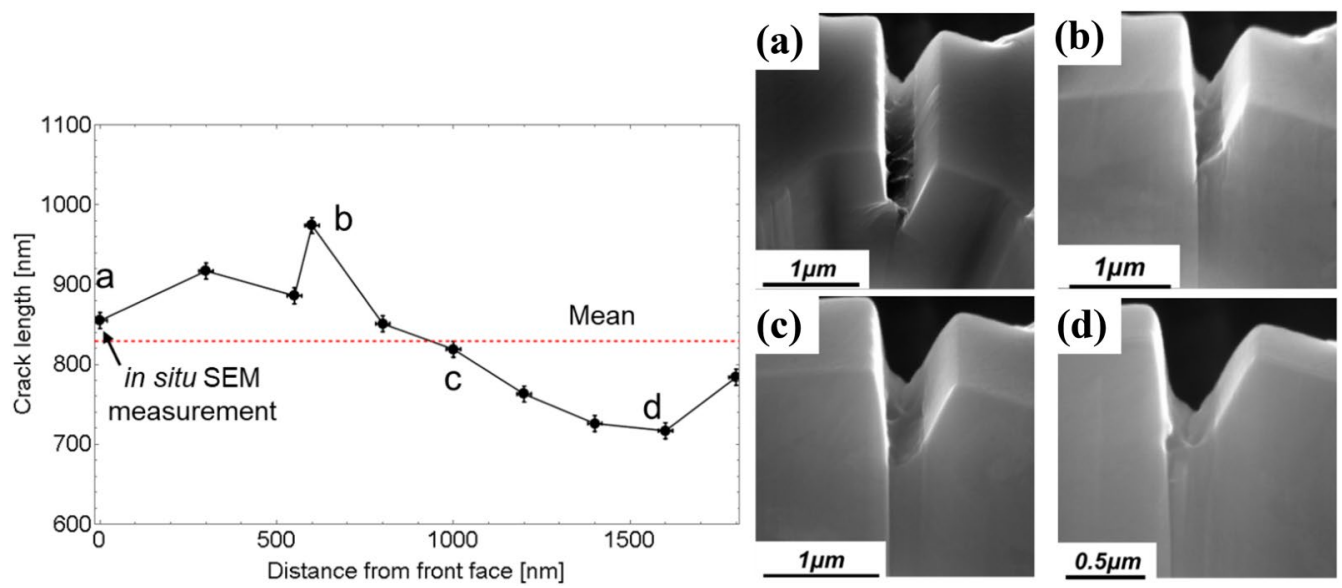

Figure 8: Crack propagation across the cantilever measured via serial sectioning (left). Corresponding SEM images as marked in the graph (a-d). The error bar is given based on ten times' measurement of one crack in depth direction and in width's direction. They have a standard error of the mean in the order $10 \mathrm{~nm}$ and $20 \mathrm{~nm}$, respectively. 
heterogeneous distribution of carbon segregating at defects like dislocations and boundaries. No obvious carbides are formed in both cases, which are believed to play a critical role in microcrack or microvoid initiation and deteriorate fracture toughness [18]. Hence, carbon should not be the key reason inducing more brittleness of martensite islands compared with WELs.

Another important factor is the grain size of the two microstructures. For lath martensite, containing abundant substructures as in our case, block boundaries act as the most efficient obstacles for dislocation motion $[36,37]$. The block size is in the order of $100 \mathrm{~nm}$ in our sample, substantially finer than the one in the literature [20,35], which strongly impedes dislocation motion in martensite islands and deteriorates ductility. In addition, grains of martensite in WELs exhibit almost equiaxed morphology, while martensite islands in dual-phase steels have a hierarchical structure with lath, blocks and packets arranging themselves complying with orientation of the prior austenite grain. This kind of structural ordering might be very detrimental for toughness. A significantly lower fracture toughness (5 MPa $\mathrm{m}^{1 / 2}$ ) of nanostructured pearlitic steels was reported when the loading direction is in parallel with lamellar microstructures. By contrast, under a perpendicular loading, fracture toughness up to $40 \mathrm{MPa} \mathrm{m}{ }^{1 / 2}$ was found [38].

\section{Damage initiation at martensite islands in DP steels}

The low toughness of martensite islands, as quantitatively proven by the micro cantilever bending test, is responsible for the crack initiation in martensite. This was also shown by in situ macroscopic tensile testing on the same DP steel combined with machine learning to statistically identify the main damage initiation sites [5]. Martensite cracking at lower strain was also found by Calcagnotto et al. [3], where a coarse-grained DP steel grade showed cleavage fractography.

Based on the measured initiation fracture toughness value, we can estimate the critical defect size for crack initiation according to Eq. (3) [21].

$$
K_{i}=Y \sqrt{\pi a_{\text {critical }}} \sigma_{y} .
$$

Here, $Y$ is dimensionless geometrical factor, varying with different geometries and $\sigma_{y}$ is the yield strength $2880 \mathrm{MPa}$. Assuming that we have a penny shape crack with $Y$ as $2 / \pi$, the estimated critical defect size is approximate $4 \mu \mathrm{m}$. Note that for a more conservative value, we take the smaller $K_{i}$ instead of $K_{i, 2 \%}$ to calculate. As the critical defect size is larger than the mean martensite island size, it is suggested that most isolated martensite islands would rather deform plastically than initiate a crack. However, large martensite islands or a banded martensite structure are sufficiently large to show crack initiation. This observation is in agreement with $[39,40]$, showing that crack initiation is preferably found at martensite bands or closely agglomerating martensite regions. Having said that, it is clear that a damage tolerance of DP steels can only be obtained by avoiding a banded microstructure.

\section{Conclusions}

We investigated the fracture behavior of martensite islands in DP800 steel and can conclude the following:

- Our martensite islands have a hierarchical substructure. Most of the carbon is located at substructure boundaries.

- Due to the small martensite, we often provoke plastic deformation of surrounding ferrite, which renders the measurement of crack initiation and growth challenging. Only 5 out of 30 samples showed negligible plasticity in ferrite.

- The martensite islands in our DP800 steel are semi-brittle, possessing a conditional fracture initiation toughness $J_{i, 2 \%}=423 \pm 22 \mathrm{~J} / \mathrm{m}^{2}$ and $K_{i, 2 \%}=10.1 \pm 0.3 \mathrm{MPa} \mathrm{m}^{1 / 2}$.

- The estimated critical defect size shows that damage initiation can happen either in very large martensite islands or in agglomerated or even banded martensite.

\section{Experimental procedure}

\section{Metallography preparation}

The material used in this work is a dual-phase steel DP800 with an ultimate tensile strength $800 \mathrm{MPa}$, which is a low-carbon steel with a few alloying elements. The chemical composition is Fe-0.13C-1.69Mn-0.19Si-0.72Cr (in wt\%). The initial sheet was first cut into $8 \times 5 \times 1.5 \mathrm{~mm}^{3}$ sized pieces. The $5 \times 1.5 \mathrm{~mm}^{2}$ sized cross section was grinded and polished by oxide polishing suspension (OPS), to prepare for the consequent microcantilever production by FIB milling, APT and EBSD. In order to reduce the FIB milling time, we targeted martensite islands which were located at the very edge of a polished surface. This required the preparation of another surface until 4000\#, aiming at minimizing the roughness at the sample edge. Besides, for microstructural investigations one additional sample was polished and subsequently etched by $1 \%$ Nital solution for $5 \mathrm{~s}$.

\section{APT analysis}

APT measurements were conducted to assess the elemental distribution in the martensite islands-particularly the $\mathrm{C}$ concentration and location-and further assist in understanding the fracture behavior. The targeted feature was lifted out onto a silicon coupon and sharpened through FIB milling (FEI Helios NanoLab 600TM) until a needle-like sharp tip was obtained. Besides, the tip was cleaned with $5 \mathrm{kV}$ and a current of $15 \mathrm{pA}$ to minimize the contamination of $\mathrm{Ga}^{+}$ions. Consecutively, 
the sharpened tip was excited atom by atom on a CAMECA instrument LEAP $^{\text {TM }} 5000 \mathrm{XR}$ using the voltage mode. The operation parameters were set as follows: the base temperature was $60 \mathrm{~K}$, the detection rate $0.5 \%$, pulse fraction $20 \%$ and pulse rate $250 \mathrm{kHz}$. Finally, a reconstruction of a three-dimensional sample tip was performed with the software package IVAS ${ }^{\oplus}$.

\section{Microcantilever production and bending test}

The microcantilevers were produced using a Zeiss Auriga ${ }^{\circledR}$ Dual beam FIB, for which the targeted feature (the martensite island) needs to be located. From the top view of the sample edge, it can be identified through topographical contrast caused by light etching effect of OPS polishing under secondary electron detector (SE). Consecutively, a small area was FIB cut carefully using a fine current $(120 \mathrm{pA})$ at the boundary of a presumably large martensite island (as imaged at the surface) to determine the three-dimensional size of the island. Only martensite islands larger than $1 \mu \mathrm{m}$ in depth are further milled by FIB. Subsequent coarse (16 nA), intermediate ( $2 \mathrm{nA})$ and fine milling (240 pA) steps at $30 \mathrm{keV}$ ion energy were used to finish the cantilever shape as shown in Fig. 9a. Finally, a through thickness notch was milled using a current of $15 \mathrm{pA}$.

Two aspects motivate the specific geometry compared to standard cantilever beam geometry: One is the very limited martensite island size. The other is to prevent plastic deformation in the remarkably softer ferrite (compare $2880 \pm 49 \mathrm{MPa}$ compressive yield strength for martensite and $147 \pm 6 \mathrm{MPa}$ CRSS for ferrite [27]). This is required to link the force-displacement curve directly to processes during crack initiation and growth at the harder martensite without being obstructed by ferrite plasticity.

The neck area ensures, to the largest extent, a full martensite microstructure in the highly stressed gauge section, while the ferrite suffers considerable low stresses due to the increased sample thickness. In Fig. 9a, $M$ denotes martensite while $F$ ferrite. $L$ is the length of the beam, from the notch to the loading point. $W$ is the thickness, $a_{0}$ the initial crack length and $B$ the cantilever width. The aspect ratios are kept constant at $W: B: a_{0}: L=1: 1: 0.2: 5$ with a nominal cantilever width of $B=1 \mu \mathrm{m}$.

The in situ fracture tests were performed in a Zeiss Gemini 500 field emission scanning electron microscope (SEM) equipped with a Hysitron indenter system. A wedge-shaped indenter is used to ensure a line-contact. It is made of tungsten carbide. We have conducted the bending test in a displacementcontrolled mode with a displacement rate of $5 \mathrm{~nm} / \mathrm{s}$. Loading and unloading segments were applied for the convenience of measuring crack growth through SEM snapshots, for which the stage tilt angle was always corrected. The snapshots during unloading segments were used to measure the crack length $a$ according to the definition provided schematically in Fig. 9b.

\section{Analysis of fracture toughness}

We apply EPFM to analyze the fracture toughness of martensite islands, because we expect a plastic zone size in the

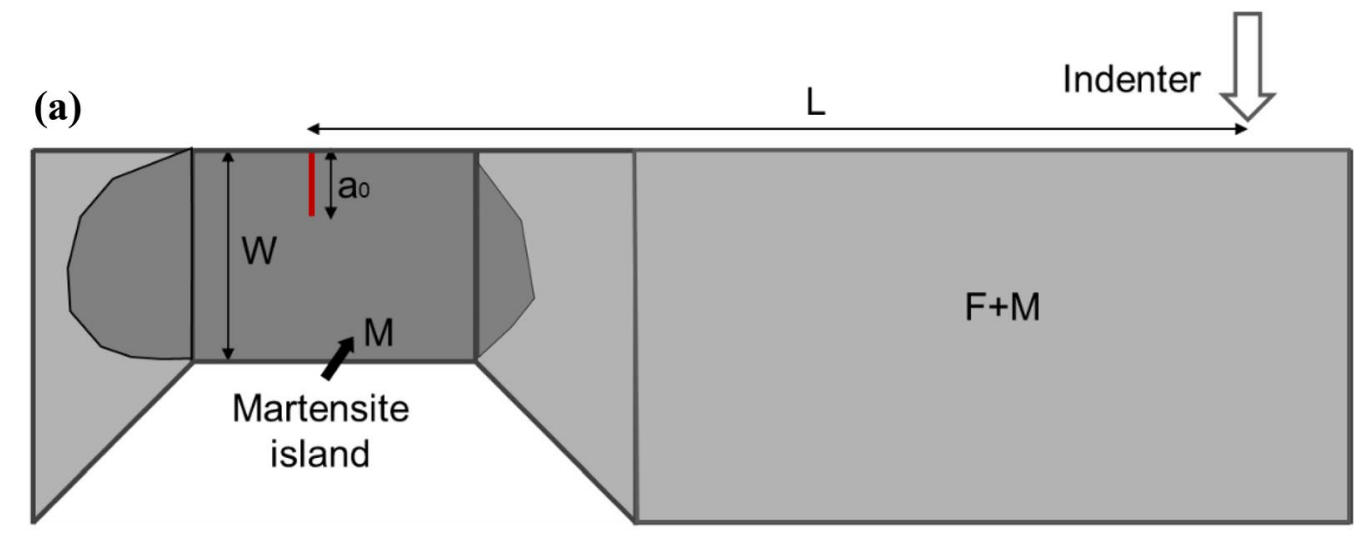

(b)

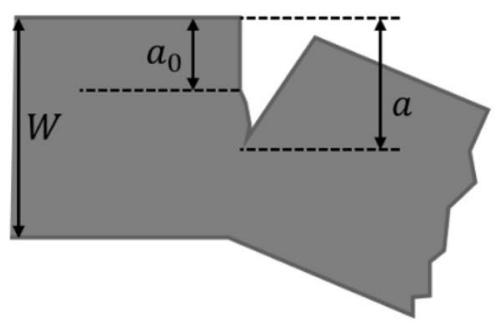

Figure 9: (a) Schematic of the cantilever geometry used in the bending testing; (b) definition and measurement of crack length. 
order of $3 \mu \mathrm{m}$ following Irwin's model and considering a reference fracture toughness of white etching layer with martensite structure $[21,23,26]$. Hence, both the elastic and plastic contributions are taken into account (see Eq. (4) [25]):

$$
J_{(i)}=\frac{\left(K_{\mathrm{IQ}(i)}\right)^{2}\left(1-v^{2}\right)}{E}+\frac{\eta A_{\mathrm{pl}(i)}}{B\left(W-a_{0}\right)},
$$

where $J_{(i)}$ is the $J$-integral of the cracked specimen upon the $i$ th loading sequence that comprises the elastic energy and the dissipated plastic energy. $K_{\mathrm{IQ}(i)}$ is the conditional stress intensity factor calculated based on the linear elastic fracture as expressed by Eq. (5):

$$
K_{\mathrm{IQ}(i)}=\frac{F_{Q(i)} L}{\mathrm{BW}^{\frac{3}{2}}} f\left(\frac{a}{W}\right)
$$

$F_{Q(i)}$ is the $i$ th loading force and $L, B, W$ are the geometrical dimensions of the tested samples as clarified in "Microcantilever production and bending test" section. Besides, $f\left(\frac{a}{W}\right)$ represents the dimensionless geometrical factor with an expression in Eq. (6) [11]:

$$
f\left(\frac{a}{W}\right)=1.46+24.36\left(\frac{a}{W}\right)-47.21\left(\frac{a}{W}\right)^{2}+75.18\left(\frac{a}{W}\right)^{3} .
$$

In the plastic part, $\eta$ is a constant normally taken as 2 . $A_{\mathrm{pl}(i)}$ is the area underneath the load versus displacement curve until the $i$ th loading, representing the integrated plastic work. Details can be found in [25].

\section{Acknowledgements}

The authors are grateful for the financial support of the German Research Foundation (Deutsche Forschungsgemeinschaft, DFG) within the Collaborative Research Center (TRR 188, "Damage Controlled Forming Processes", 278868966) in project B03 "Understanding the damage initiation at microstructural scale”.

\section{Funding}

Open Access funding enabled and organized by Projekt DEAL..

\section{Data availability}

The raw data used in this work can be made available upon request.

\section{Declarations}

Conflict of interest On behalf of all authors, the corresponding author states that there is no conflict of interest.
Open Access This article is licensed under a Creative Commons Attribution 4.0 International License, which permits use, sharing, adaptation, distribution and reproduction in any medium or format, as long as you give appropriate credit to the original author(s) and the source, provide a link to the Creative Commons licence, and indicate if changes were made. The images or other third party material in this article are included in the article's Creative Commons licence, unless indicated otherwise in a credit line to the material. If material is not included in the article's Creative Commons licence and your intended use is not permitted by statutory regulation or exceeds the permitted use, you will need to obtain permission directly from the copyright holder. To view a copy of this licence, visit http://creativecommons.org/licenses/by/4.0/.

\section{References}

1. H. Li, S. Gao, Y. Tian, D. Terada, A. Shibata, N. Tsuji, Influence of tempering on mechanical properties of ferrite and martensite dual phase steel. Mater. Today 2, S667 (2015)

2. C.C. Tasan, M. Diehl, D. Yan, M. Bechtold, F. Roters, L. Schemmann, C. Zheng, N. Peranio, D. Ponge, M. Koyama, An overview of dual-phase steels: advances in microstructure-oriented processing and micromechanically guided design. Annu. Rev. Mater. Res. 45, 391 (2015)

3. M. Calcagnotto, Y. Adachi, D. Ponge, D. Raabe, Deformation and fracture mechanisms in fine-and ultrafine-grained ferrite/ martensite dual-phase steels and the effect of aging. Acta Mater. 59(2), 658 (2011)

4. D.K. Matlock, J.G. Speer, E. De Moor, P.J. Gibbs, Recent developments in advanced high strength sheet steels for automotive applications: an overview. Jestech 15(1), 1 (2012)

5. C. Kusche, T. Reclik, M. Freund, T. Al-Samman, U. Kerzel, S. Korte-Kerzel, Large-area, high-resolution characterisation and classification of damage mechanisms in dual-phase steel using deep learning. PLoS ONE 14(5), e0216493 (2019)

6. T. Sirinakorn, S. Wongwises, V. Uthaisangsuk, A study of local deformation and damage of dual phase steel. Mater. Des. 64, 729 (2014)

7. Q. Lai, O. Bouaziz, M. Gouné, L. Brassart, M. Verdier, G. Parry, A. Perlade, Y. Bréchet, T. Pardoen, Damage and fracture of dualphase steels: influence of martensite volume fraction. Mater. Sci. Eng. A. 646, 322 (2015)

8. G. Dehm, B.N. Jaya, R. Raghavan, C. Kirchlechner, Overview on micro-and nanomechanical testing: new insights in interface plasticity and fracture at small length scales. Acta Mater. 142, 248 (2018)

9. H. Ghassemi-Armaki, R. Maaß, S. Bhat, S. Sriram, J. Greer, K. Kumar, Deformation response of ferrite and martensite in a dual-phase steel. Acta Mater. 62, 197 (2014)

10. Y. Wang, R. Fritz, D. Kiener, J. Zhang, G. Liu, O. Kolednik, R. Pippan, J. Sun, Fracture behavior and deformation mechanisms in nanolaminated crystalline/amorphous micro-cantilevers. Acta Mater. 180, 73 (2019) 
11. K. Matoy, H. Schönherr, T. Detzel, T. Schöberl, R. Pippan, C. Motz, G. Dehm, A comparative micro-cantilever study of the mechanical behavior of silicon based passivation films. Thin Solid Films 518(1), 247 (2009)

12. B.N. Jaya, C. Kirchlechner, G. Dehm, Can microscale fracture tests provide reliable fracture toughness values? A case study in silicon. J. Mater. Res. 30(5), 686 (2015)

13. S. Wurster, C. Motz, R. Pippan, Characterization of the fracture toughness of micro-sized tungsten single crystal notched specimens. Philos. Mag. 92(14), 1803 (2012)

14. J. Ast, M. Göken, K. Durst, Size-dependent fracture toughness of tungsten. Acta Mater. 138, 198 (2017)

15. A.K. Saxena, S. Brinckmann, B. Völker, G. Dehm, C. Kirchlechner, Experimental conditions affecting the measured fracture toughness at the microscale: Notch geometry and crack extension measurement. Mater. Des. 191, 108582 (2020)

16. S. Morito, H. Tanaka, R. Konishi, T. Furuhara, A.T. Maki, The morphology and crystallography of lath martensite in $\mathrm{Fe}-\mathrm{C}$ alloys. Acta Mater. 51(6), 1789 (2003)

17. C. Du, J. Hoefnagels, S. Kölling, M. Geers, J. Sietsma, R. Petrov, V. Bliznuk, P. Koenraad, D. Schryvers, B. Amin-Ahmadi, Martensite crystallography and chemistry in dual phase and fully martensitic steels . Mater. Charact. 139, 411 (2018)

18. R. Dolby and K. JF: Toughness of martensitic and martensiticbainitic microstructures with particular reference to heat affected zones in welded low alloy steels (1972).

19. S. Li, G. Zhu, Y. Kang, Effect of substructure on mechanical properties and fracture behavior of lath martensite in $0.1 \mathrm{C}-1.1$ Si-1.7 Mn steel. J. Alloys Compd. 675, 104 (2016)

20. Y. Liang, S. Long, P. Xu, Y. Lu, Y. Jiang, Y. Liang, M. Yang, The important role of martensite laths to fracture toughness for the ductile fracture controlled by the strain in EA4T axle steel. Mater. Sci. Eng. A. 695, 154 (2017)

21. T.L. Anderson, Fracture Mechanics: Fundamentals and Applications (CRC Press, Boca Raton, 2017).

22. R. Pippan, S. Wurster, D. Kiener, Fracture mechanics of micro samples: fundamental considerations. Mater. Des. 159, 252 (2018)

23. A.K. Saxena, A. Kumar, M. Herbig, S. Brinckmann, G. Dehm, C. Kirchlechner, Micro fracture investigations of white etching layers. Mater. Des. 180, 107892 (2019)

24. A. Standard, E399-90 Standard Test Method for Plane Strain Fracture Toughness of Metallic Materials (American Society for Testing and Materials, Philadelphia, 1993).

25. E. Astm: Standard test method for measurement of fracture toughness. ASTM, Annual Book of Standards. 3 (1820)

26. J. Ast, M. Ghidelli, K. Durst, M. Göken, M. Sebastiani, A. Korsunsky, A review of experimental approaches to fracture toughness evaluation at the micro-scale. Mater. Des. 173, 107762 (2019)
27. C. Tian, D. Ponge, L. Christiansen, C. Kirchlechner, On the mechanical heterogeneity in dual phase steel grades: activation of slip systems and deformation of martensite in DP800. Acta Mater. 183, 274 (2020)

28. N. Vajragupta, V. Uthaisangsuk, B. Schmaling, S. Münstermann, A. Hartmaier, W. Bleck, A micromechanical damage simulation of dual phase steels using XFEM. Comput. Mater. Sci. 54, 271 (2012)

29. O. Towers, S. Garwood, Influence of Crack Depth on Resistance Curves for Three-Point Bend Specimens in HY130, in Fracture Mechanics, vol. 17 (ASTM International, West Conshohocken, 1986).

30. X.-K. Zhu, J.A. Joyce, Review of fracture toughness (G, K, J, CTOD, CTOA) testing and standardization . Eng. Fract. Mech. 85, $1(2012)$

31. J. Krawczyk, J. Pacyna, P. Bała, Fracture toughness of steels with nickel content in respect of carbide morphology . Mater. Sci. Technol. 31(7), 795 (2015)

32. E. Pavlina, C. Van Tyne, Correlation of yield strength and tensile strength with hardness for steels. J. Mater. Eng. Perform. 17(6), 888 (2008)

33. B.N. Jaya, S. Goto, G. Richter, C. Kirchlechner, G. Dehm, Fracture behavior of nanostructured heavily cold drawn pearlitic steel wires before and after annealing. Mater. Sci. Eng. A. 707, 164 (2017)

34. Y. Li, D. Raabe, M. Herbig, P.-P. Choi, S. Goto, A. Kostka, H. Yarita, C. Borchers, R. Kirchheim, Segregation stabilizes nanocrystalline bulk steel with near theoretical strength. Phys. Rev. Lett. 113(10), 106104 (2014)

35. A. Kumar, A. Saxena, C. Kirchlechner, M. Herbig, S. Brinckmann, R. Petrov, J. Sietsma, In Situ study on fracture behaviour of white etching layers formed on rails. Acta Mater. 180, 60 (2019)

36. C. Du, J. Hoefnagels, R. Vaes, M. Geers, Block and sub-block boundary strengthening in lath martensite. Scripta Mater. 116, 117 (2016)

37. S. Morito, H. Yoshida, T. Maki, X. Huang, Effect of block size on the strength of lath martensite in low carbon steels. Mater. Sci. Eng. A. 438, 237 (2006)

38. A. Hohenwarter, B. Völker, M.W. Kapp, Y. Li, S. Goto, D. Raabe, R. Pippan, Ultra-strong and damage tolerant metallic bulk materials: a lesson from nanostructured pearlitic steel wires. Sci. Rep. 6, 33228 (2016)

39. M. Ayatollahi, A.C. Darabi, H. Chamani, J. Kadkhodapour, 3D micromechanical modeling of failure and damage evolution in dual phase steel based on a real 2D microstructure. Acta Mech. Solida Sin. 29(1), 95 (2016)

40. A. Ramazani, Z. Ebrahimi, U. Prahl, Study the effect of martensite banding on the failure initiation in dual-phase steel. Comput. Mater. Sci. 87, 241 (2014) 